УдК 101.1:316

\title{
ТУРИЗМ КАК ЭЛЕМЕНТ СФЕРЫ СОЦИАЛЬНОГО БЛАГОПОЛУЧИЯ
}

\author{
Александрова Мария Александровна, \\ aleksandrova@tpu.ru
}

\begin{abstract}
Национальный исследовательский Томский политехнический университет, Россия, 634050, г. Томск, пр. Ленина, 30.
\end{abstract}

\begin{abstract}
Александрова Мария Александровна, ведущий эксперт Учебно-методического отдела Национального исследовательского Томского политехнического университета.
\end{abstract}

\begin{abstract}
Актуальность исследования определяется динамичностью развития сферы туризма, феномен которого рассматривается в качестве элемента сферы социального благополучия. Автор анализирует основные характеристики туризма, обеспечивающие его развитие и вовлечение в туризм глобального общества, а также выявляет роль и значение туризма в современном обществе. Цель: охарактеризовать туризм в качестве элемента сферы социального благополучия. Методы: структурно-функциональный анализ, теория структурного функционализма, которая позволяет охарактеризовать проблематику феномена туризма, ориентированную на достижение социального благополучия посредством самореализации и индивидуального развития личности. В соответствии с поставленными задачами исследования был использован аналитический метод, с помощью которого рассмотрены научные труды, ориентированные на социально-философский анализ туризма и благополучия, что позволило выявить значимость феномена туризма в современном глобальном обществе. Применен феноменологический подход, позволивший осмыслить туризм как феномен бытия общества, который является важной сферой его жизни и влияет на ощущения человеком счастья и субъективного благополучия, способствующего, в свою очередь, формированию благополучия социального в целом и росту качества жизни. Результаты. В современном обществе благополучие нельзя свести только к материальным факторам, поскольку оно включает в себя и социокультурные аспекты. Рассматривая туризм как способ реализации благополучия, автор приходит к выводу о развитии личностных качеств человека посредством формирования его субъективного благополучия. Туризм как феномен глобального общества может расширить личное пространство человека, что приводит к реализации его индивидуальных стратегий развития и самосовершенствования. Очевидна значимость туризма в формировании субъективного благополучия, и это зависит от значения, которое конкретный человек придает туризму и целям, $с$ ним связанным. Все это подтверждает социальное значение туризма как элемента сферы социального благополучия.
\end{abstract}

Ключевые слова: Туризм, путешествие, массовый туризм, индивидуальный туризм, общество досуга, благополучие.

Сегодня туризм охватывает все страны и континенты. Общее число туристов в мире в 2017 г. составило 1,322 млрд человек, согласно данным Всемирной туристской организации (ЮНВТО), в 2008 г. - 0,922 млрд человек. За последние 10 лет число путешественников выросло более чем на 40 \%. На начало 2017 г. население Земли составляло приблизительно 7,577 млрд человек. Следовательно, в среднем практически каждый пятый житель планеты путешествовал в 2017 г. [1]. Масштаб и динамика развития туризма оказывают существенное влияние на современное глобальное общество.

В контексте социальной философии туризм - деятельность, способная оказать на индивида внешнее воздействие и существующая вне зависимости от конкретной лич- 
ности. В соответствии с концепцией социального факта Э. Дюркгейма социальная активность, в том числе и в сфере туризма, представлена морфологическими фактами (демографическими, технологическими, экологическими) и коллективными представлениями [2]. Именно коллективные представления раскрывают сущность феномена туризма в современном обществе. Туризм вне коллективного принятия не смог бы сформироваться как элемент сферы общественной жизни, поскольку представления каждого индивида имеют зависимость от коллективного и подвержены его непосредственному влиянию, вплоть до полного принятия индивидом коллективных представлений.

Туризм, благодаря своей массовости, стал неотъемлемым элементом современного глобального общества. Основные черты современного общества, способствующие развитию туризма, сформировались под влиянием промышленной революции, обеспечившей кратный рост свободного времени, а также под влиянием развития широкой сети транспортной инфраструктуры, обеспечившей положительную динамику мобильности жителей всех стран мира, расширившей межкультурное взаимодействие представителей разных стран и народов мира. Ставшее реальностью общество «досуга» на первый план выдвигает качественное наполнение свободного времени. Сокращение рабочего времени, снижение физической нагрузки и повышение уровня образования привели к повышению спроса на более качественный туристический продукт и расширению круга туристических направлений и видов туристской деятельности [3].

В последние годы основной акцент в организации досуга сместился от отдыха и развлечений к познавательным мероприятиям, лечебным и оздоровительным процедурам. В мире в целом повышается стремление людей к личному развитию. Изменилось и понимание семантики досуга. От пассивного времяпрепровождения (пляж, море, солнце) современный человек ориентируется на активно-познавательный вид досуговой деятельности. Трансформация восприятия обществом туризма как средства реализации досуговых потребностей нашла отражение и в научных исследованиях, ориентированных на изучение общественного досуга и отдыха. В мировой исследовательской практике уже более 40 лет успешно реализуется проект TObeWell (Tourism, Wellbeing and Ecosystem Services), направленный на развитие туризма как ресурса формирования культуры, здоровья и благополучия в глобальном обществе.

Каждая из стран мира, каждый отдельно взятый регион, туристская дестинация обладает определенным туристским потенциалом, основанным на определенных туристских ресурсах (природных, культурных, исторических и пр.) и представляющим интерес для определенной категории туристов. Вместе с тем туризм является важным ресурсом благополучия в обществе.

Рассматривая туризм как элемент социальной сферы важно разграничивать понятия «путешествие» и «туризм», поскольку, несмотря на очевидную неразрывную связь этих понятий, они не являются тождественными. Путешествие может быть образом жизни человека или же формой трудовой деятельности, служащей источником его дохода. Так, к примеру, путешественниками являются члены Русского географического общества - общественной организации, основной целью которой является сбор и распространение достоверных географических сведений. Путешествие, так же как и туризм, - понятие сложное и многогранное. Туризм охватывает поездки с целью организации досуга, ради удовольствия, с оздоровительными и рекреационными целями и пр. В настоящее время общепринято выделять номенклатуру видов туризма: рекреационный, познавательный, культурно-оздоровительный, лечебно-оздоровительный, развлекательный, событийный, спортивный, экскурсионный, деловой, культурный и пр. Туризм является закономерным процессом, присущим развитию современной жизни об- 
щества, в который вовлечена большая часть глобального общества. В процессе туризма меняется не только само общество, но и содержание окружающей его реальности на основе переработки и трансляции социального опыта, приобретенного посредством туризма. Туризм как элемент сферы общественной жизни берет свое начало с Античности, когда основными целями путешественников преимущественно являлись торговля и паломничество, военные походы, путешествия с целью открытия новых территорий, дипломатические поездки и пр. С древних времен путешественниками формировались подробные описания различных территорий, которые они посещали и изучали с целью развития и укрепления межкультурных взаимоотношений. Вплоть до середины XIX века походы и путешествия, совершаемые с разнообразными целями, укрепляли взаимоотношения людей и расширяли географические, культурные и научные познания. Иными словами, путешествия не имели выраженных целей туризма, а, скорее, носили вынужденный и необходимый характер, и, конечно, путешествия не совершались с целью получения удовольствия или реализации досуга. Феномен туризма с момента своего возникновения представляет собой важный элемент жизни людей во всех многогранных проявлениях, в том числе туризм затрагивает вопросы организации досуга, сферу отношений между людьми, взаимовлияние людей и окружающей среды, а также взаимодействие культур разных стран и народов.

Обратимся к туристскому глоссарию Всемирной организации по туризму (UNWTO) в части определения понятий «путешествие» и «туризм» [4]:

- туризм относится к деятельности лиц, путешествующих с целью отдыха;

- путешествие - перемещение между различными географическими местами для любых целей и любой продолжительности. В глоссарии отмечено, что туризм является одним из видов путешествия.

Очевидны различия понятий «путешествие» и «туризм»: путешествие не является целью поездки или передвижения, а служит лишь средством, посредством которого человек достигает поставленной задачи, например, по изучению какой-либо территории. Результатом трансформации путешествия от средства к непосредственной цели свершаемой человеком активности (деятельности) является туризм.

В условиях глобализации особую актуальность приобретает межкультурное взаимодействие, поскольку туризм представляет собой сферу деятельности социума, где встречаются люди различных культур. Все более насущными становятся проблемы целей и потребностей туристов, что, в свою очередь, приводит к дифференциации видов туризма. Так, например, современный культурный туризм имеет множество форм и проявлений. Автор книги «Исследования культурного туризма» Мелани Смит приводит классификацию типов культурного туризма:

- исторический (типичные объекты посещения: замки, дворцы, деревенские дома, археологические памятники, исторические памятники музеи, религиозные достопримечательности);

- искусствоведческий (предполагает посещение театров, концертов, галерей, фестивалей, карнавалов и других мероприятий);

- творческий (фотографии, живопись, керамика, кулинария, изучение языков, ремесла);

- городской (посещение исторических городов, возрожденных промышленных городов, знакомство с произведениями искусства, шопинг, знакомство с ночной жизнью городов);

- сельский (посещение деревней, ферм, экомузеев, культурных ландшафтов, национальных парков и пр.); 
- этнический (пустынные или горные маршруты, посещение этнических центров, племен, знакомство с искусствами и ремеслами, культурные мероприятия, фестивали);

- современный (посещение тематических парков и достопримечательностей, шопинг-центров, поп-концертов, спортивных событий, медиасобытий и съемочных площадок, объектов индустриального наследия, музеев моды и дизайна) [5].

Туризм в настоящее время присущ всем слоям общества и с точки зрения теории социальной стратификации М. Вебера и П. Сорокина способен служить фактором классовой принадлежности индивида. Чем выше иерархическая принадлежность индивида в социуме, тем, как правило, шире его потенциальные возможности в осуществлении туристской активности. Многообразие представленных возможностей в сфере туризма формирует диверсификацию потребителей. Основное отличие тенденции диверсификации (индивидуализации) от массового конвейерного туризма заключается в основной цели поездки: для туриста массового конвейерного туризма нет большого различия между культурой и досугом (для такого туриста размыта ценность объекта того или иного вида туризма: аутентичность туристских объектов и музейных экспонатов или ценность уникальных природных достопримечательностей и пр.), в дифференцированном (индивидуализированном) туризме - человек совершает путешествие с конкретной целью (познание определенных аутентичных культурных, природных, религиозных или иных заинтересовавших его объектов, посещение определённых мероприятий, знакомство с конкретной культурой, получение новых впечатлений и эмоций в экстремальных поездках и пр.). Каждый вид туризма обладает разными ресурсами и каждый в разной степени способен обеспечить разнообразные потребности человека в досуге и отдыхе. При этом, следует отметить, что удовлетворение потребностей туриста способствует формированию благополучия. С расширением и ростом качественных туристских потребностей на первый план выходят мотивация и индивидуальные приоритеты туриста. Современные туристы ищут отдаленные, нетронутые человеком территории (диапазон таких объектов весьма широк - от диких пляжей до полетов в космос). Сегодня человек живет в мультикультурном обществе, что влечет за собой необходимость доступного взаимного познания и интерпретации культур разных стран и народов. Туризм, несомненно, играет определяющую роль в формировании национальной, региональной и местной культурной идентичности туриста, способствует повышению уровня социального благополучия и толерантности. Благополучие в современном обществе не исчерпывается только материальным благосостоянием. Оно включает многообразие социальных и социокультурных параметров. Благополучие как самореализация в личностном и социальном плане, как успешность в достижении поставленных целей отражает жизненные стратегии современного человека. Туризм в наибольшей степени способен обеспечить благополучие человека. Многообразие видов туризма позволяет каждому найти собственную нишу реализации стратегии своего развития. Взаимосвязь и взаимовлияние туризма в различных его формах на становления и развитие благополучия являются очевидными. Именно стремление человека получать удовольствие от встречи с неизведанным природным или культурным объектом толкает его начать поиск собственного, индивидуального и уникального опыта познания мира. Путешествие как постижения себя в мире разнообразия стран, народов и культур увеличивает субъективное восприятие мира, способствует формированию толерантности личности. Определим основные отличия массового конвейерного туризма и качественно нового дифференцированного (индивидуального) туризма: для потребителей конвейерных туров нет большой разницы между культурой и досугом, турист готов принять недостоверные достопримечательности, занимает обособленную позицию по отношению к 
представителям иной культуры, в то время как турист, выбравший свой тур исходя из своих персональных потребностей (культурно-исторических, коммуникативных, познавательных, эстетических, эмоционально-психологических и пр.), имеет основной целью познание культуры, посещение мероприятия, природного объекта, его привлекает аутентичность посещаемых объектов, ему важна уникальность той или иной культуры, объекта, события и достоверность увиденного; такой турист имеет желание установить контакт с представителями иной культуры (доминирует необходимость формирования собственной социокультурной идентичности, духовной самореализации).

В развитии индустрии туризма некогда основополагающими были базовые потребности, без которых невозможно существование индустрии туризма в виде транспортной инфраструктуры, средств размещения, питания, обеспечения безопасности путешественников. Теперь же развитие индустрии туризма обусловлено высокой осведомлённостью, требовательностью и дифференциацией путешественников. Туризм в настоящее время чрезвычайно чувствителен к изменениям экономической и политической ситуации, к социально-культурным и экологическим факторам, а также к факторам, связанным с обеспечением мер безопасности в регионе пребывания, отправления и по маршруту путешествия в целом. Современный туристский продукт не может быть унифицирован: он должен быть дифференцированным, разнообразным и личностно ориентированным [6].

По мнению ряда исследователей, феномен туризма сформировался в качестве социальной стратегии познания мира за счет усложнения структур глобального общества и присущих ему фундаментальных ценностей. Феномен туризма отражает собой основные черты глобального общества - мобильность, потребительскую активность, визуализацию, виртуализацию, глобализацию и пр.

Сегодня туризм стал неотъемлемой частью жизни современного общества и охватил все страны и континенты. Масштаб и динамика развития туризма оказывают существенное влияние на современное глобальное общество. Туризм в настоящее время распространен в обществе повсеместно и оказывает значительное влияние на все элементы сферы общественной жизни. Туризм становится основой социального благополучия, выраженного не только и не столько материальной составляющей, а ориентированного на духовное развитие личности, способствует повышению качества жизни, укреплению международных и межкультурных коммуникаций, способствующих формированию мира на Земле. Благополучие как основа личностной и социальной самореализации и успешности в достижении целей формирует жизненные стратегии человека. Туризм представляет собой совокупность отношений и единство связей и явлений, которые сопровождают человека в путешествиях.

Научный подход к формированию благополучия туриста непосредственно через потребность в улучшении своего субъективного самочувствия и состояния здоровья наиболее полно представлен работами S. McCabe, S. Johnson, A. Coghlan [7-10]. Благополучие в равной степени представляет интерес для создателей политики в области туризма и непосредственных участников туристского рынка, заинтересованных в целевом маркетинге.

В настоящее время благополучие как социальный и культурный феномен все чаще выступает показателем эффективного развития общества и конкретного человека. В исследованиях ряда российских и зарубежных ученых проблема благополучия рассматривается как ресурс развития человеческого капитала. Социальное благополучие это высшая социальная ценность, социальный идеал, область социальной оптимальности, с которой связаны жизненно важные интересы человечества. 
Российский опыт исследования влияния туризма на благополучие и качественный активный досуг находится лишь в процессе становления. В фундаментальном исследовании В.Ю. Воскресенского «Международный туризм» [11] намечены пути развития туризма, которые в дальнейшем, при определенных инвестициях, способны активизировать туристскую отрасль как ресурс социального благополучия, анализируется европейский опыт культурного, образовательного и экологического туризма и приводятся примеры эффективного использования культурного европейского назначения для успешного развития туризма.

Благополучие может быть оценено с гедонистических и эвдемонистических позиций. В гедонистическом подходе акцент делается на счастье, обычно определяемом как наличие положительного аффекта и отсутствие отрицательного аффекта, в эвдемонистическом - акцент делается на полном и глубоком удовлетворении жизнью.

За последние несколько десятилетий наиболее активно благополучие исследовано в психологии, в значительной степени такими учеными, как Diener E. [12], который сосредоточился на исследовании субъективного благополучия. По его мнению, благополучие считается субъективным, поскольку люди оценивают для себя степень, в которой они испытывают чувство благополучия. Субъективному благополучию присущ высокий уровень положительного аффекта, низкий уровень отрицательного аффекта и высокая степень удовлетворенности жизнью. Понятие субъективного благополучия, оцененное таким образом, часто взаимозаменяемо с понятием «счастье». Таким образом, максимизация благосостояния рассматривается как максимизация чувства счастья. В социально-культурном аспекте туризм как элемент сферы социального благополучия проанализирован в работах российских ученых, таких как О.Т. Лойко, С.В. Дрыга [13].

Исходя из теории социологический системы В. Парето, к определенным нелогическим действиям индивида его подталкивает и определённый психический склад. В обществе каждый индивид осуществляет определенное действие, обусловленное его психическим состоянием. Несомненно, высокий уровень жизни индивида обеспечивает и его позитивное психоэмоциональное состояние, что находит отражение и в его деятельности.

В соответствии с основными положениями исследовательского проекта TObeWELL определены ключевые аспекты благополучия: высокий уровень жизни, здоровье, безопасность, хорошие социальные взаимоотношения и свобода выбора. Следовательно, более высоким уровнем благополучия обладают представители наиболее богатых и наиболее посещаемых туристами стран, поскольку эти люди имеют высокий уровень жизни, а также условия жизни, характеризующиеся высоким уровнем безопасности, позитивными настроениями гражданского общества, что подтверждается данными статистики Всемирной организации по туризму (UNWTO) и официальными данными Международного валютного фонда (см. таблицу) [14, 15].

Лидирующие позиции занимают страны либо с огромными запасами природных ресурсов, либо с очень развитой технологичной экономикой. Стандарты жизни в таких государствах весьма высокие. Конечно, нельзя забывать об объективных особенностях данных списков. Так, например, больше всех туристов в 2017 г. привлекла Франция, вторую строчку заняла Испания (впервые за долгие годы опередив США), в десятку попали и страны, не такие благополучные, как лидеры списка, но имеющие достойный туристский потенциал и предлагающие дешевые услуги - это Турция, Мексика и Таиланд. Однако в лидерах выездного туризма, помимо стран, возглавляющих топ-10 мировой экономики, есть такие страны, как Россия, попавшая в данный список скорее как наиболее многочисленная страна - поскольку список составлен по доле расходов тури- 
стов той или иной страны в общем числе расходов лиц, совершивших путешествие в 2017 г. В субъективных проявлениях граждане ощущают комфорт, общий рост качества жизни, удовлетворенность потребностей в саморазвитии и самореализации от поездки, в объективных проявлениях - имеют материальные ресурсы на совершение поездки: чем богаче общество того или иного государства и чем больше оно имеет свободного времени и ресурсов для организации своего досуга, тем оно благополучнее, в том числе и посредством совершаемых им туристских поездок.

Таблица. Топ-10 стран по итогам 2017 г. по популярности среди туристов. Страны, граждане которых наиболее часто совершают поездки, и самые богатые страны (по абсолютному показателю ВВП)

Table. TOP 10 countries by the end of 2017 in popularity among tourists, the countries which citizens most often travel, and the richest countries (in absolute terms of GDP)

\begin{tabular}{|c|c|c|}
\hline $\begin{array}{c}\text { Топ-10 самых популярных среди } \\
\text { туристов стран, млн чел. } \\
\text { World's } 10 \text { most popular tourist } \\
\text { destinations, million people }\end{array}$ & $\begin{array}{l}\text { Топ-10 самых богатых стран мира } \\
\text { по абсолютному показателю ВВП, } \\
\text { млрд \$ } \\
\text { World's } 10 \text { most richest countries in the } \\
\text { world in absolute GDP, billion \$ }\end{array}$ & $\begin{array}{c}\text { Топ-10 стран по уровню рас- } \\
\text { ходов на выездной туризм } \\
\text { Top } 10 \text { countries in terms of } \\
\text { expenditure on outbound tour- } \\
\text { ism }\end{array}$ \\
\hline $\begin{array}{l}\text { 1. Франция/France }-86,9 \\
\text { 2. Испания/Spain }-81,8 \\
\text { 3. США/USA - 75,9 } \\
\text { 4. Китай/China }-60,7 \\
\text { 5. Италия/Italy }-58,3 \\
\text { 6. Мексика/Mexico }-39,3 \\
\text { 7. Великобритания } \\
\text { United Kingdom } \\
\text { of Great Britain }-37,7 \\
\text { 8. Турция/Turkey - 37,6 } \\
\text { 9. Германия/Germany - 37,5 } \\
\text { 10. Таиланд/Thailand - 35, } 4\end{array}$ & $\begin{array}{ll}\text { 1. } & \text { США/USA - 19284,99 } \\
\text { 2. } & \text { Китай/China - 12263,43 } \\
\text { 3. } & \text { Япония/Japan }-4513,75 \\
\text { 4. } & \text { Германия/Germany }-3591,69 \\
\text { 5. } & \text { Великобритания/United Kingdom } \\
& \text { of Great Britain }-2885,48 \\
\text { 6. } & \text { Франция/France }-2537,92 \\
\text { 7. } & \text { Индия/India }-2487,94 \\
\text { 8. } & \text { Италия/Italy }-1901,67 \\
\text { 9. } & \text { Бразилия/Brazil - 1556,44 } \\
\text { 10. } & \text { Канада/Canada - 1530,7 }\end{array}$ & $\begin{array}{l}\text { 1. Китай/China } \\
\text { 2. США/USA } \\
\text { 3. Германия/Germany } \\
\text { 4. Великобритания/Great } \\
\quad \text { Вritain } \\
\text { 5. Франция/France } \\
\text { 6. Австралия/Australia } \\
\text { 7. Канада/Canada } \\
\text { 8. Россия/Russia } \\
\text { 9. Южная Kopeя/South Korea } \\
\text { 10. Италия/Italy }\end{array}$ \\
\hline
\end{tabular}

Интерпретация благополучия с гедонических позиций предполагает положительное влияние и отрицательное влияние на уровень ощущения счастья, поскольку удовлетворенность жизнью не является строго гедонической концепцией и включает в себя когнитивную оценку условий жизни.

Однако благополучие рассматривается также с позиций концепции эвдемонии не только как ощущение счастья (позитивной аффективности и удовлетворенности), а как процесс выполнения или реализации даймония (с греческого - «божественный») или истинной природы, т. е. выполнения тех добродетельных потенциалов и жизни, которые изначально предназначались для жизни. Иначе говоря, благополучие - это не столько конечный результат или конечное состояние, сколько именно процесс. Эвдемонический взгляд на благополучие прослеживается от Аристотеля и согласуется с различными интеллектуальными традициями XX в., включая гуманистическую психологию.

Указанные подходы к благополучию - гедонизм и эвдемонизм - основаны на различных представлениях о сущности человеческого бытия. Гедонический подход использует стандартную социологическую модель, которая изначально считает человека восприимчивым к окружающей его социальной и культурной среде. Эвдемонизм направлен на раскрытие имеющегося потенциала человеческой природы и на определение условий, которые оказывают непосредственное влияние на сущность человеческой природы. Мы придерживаемся философских основ эвдемонии и гедонизма как концеп- 
ций благополучия. При этом эвдемонизм присущ в большей степени субъективным проявлениям благополучия, а гедонизм - объективным. Основной смысл эвдемонии заключается непосредственно в жизни человека, индивидуальной и неповторимой, ориентированной на достижение определенных индивидуумом целей, а не в благополучии как таковом. Благополучие не является самоцелью, а является результатом протекающего жизненного процесса, итогом которого и служат проявления чувства радости и счастья, обретение смысла жизни и реализации планов. При этом благополучие, рассматриваемое с позиции эвдемонии, имеет значительное совпадение с субъективным благополучием в ракурсе гедонической перспективы [8].

Такие темы, как благополучие, счастье, оптимизм, юмор, положительные эмоции, сильные стороны характера и прочие характеристики личности, которые в целом относятся к исследованию качества жизни, рассматривают исследователи позитивной психологии (например, С. Филеп). Позитивная психология - это растущая, глобальная область исследований психологии, которая процветала в последнее десятилетие, но ее туристические приложения недостаточно развиты в настоящий момент. Выделяются три связи туризма и позитивной психологии:

- позитивное психологическое исследование счастья и его использование в концептуализации и измерении удовлетворяющего, положительного и счастливого туристского опыта;

- положительные психологические черты характера, сильные стороны личности и их потенциал, ориентированные на глобальные ценности туризма образования;

- положительные исследования психологии юмора и его значение в продвижении туристских продуктов на рабочем месте [16].

Наметившиеся связи всеобъемлющи и касаются различных контекстов туризма, а также всех его непосредственных участников: туристов и местных жителей туристских дестинаций, работников инфраструктуры туризма и менеджеров турагентств и туроператоров, студентов и преподавателей образовательных организаций, реализующих образовательные программы, ориентированные на туризм [17]. Две ключевые задачи развития туризма и позитивной психологии сведены к таким проблемам, как:

- проблемы преодоления барьеров в исследованиях сферы туризма, связанных с замкнутостью, ориентированностью на узкие области исследований; следует осознать необходимость ориентации в исследованиях на различные области научного знания, что позволит в дальнейшем понять весь потенциал имеющихся перспектив сферы туризма для глобального общества и применять исследовательские методы, возможно, не всегда свойственные привычным исследованиям в сфере туризма, но имеющих важное значение в раскрытии основных характеристик, способствующих повышению качества жизни общества;

- проблемы, связанные с необходимостью ориентации на субъективные выгоды от туризма и позитивной психологии, связанные с физическими показателями здоровья, с целью определения оптимального человеческого функционирования.

Рост значимости туризма в качестве ресурса формирования благополучия представляет интерес правительств государств мира, рассматривающих пропаганду туризма через трансляцию традиционных ценностей и культурного наследия своей страны как значимую политическую и социальную тенденцию, ориентированную на организацию досуга граждан. Кроме того, приоритетной является задача формирования инструментов, позволяющих удовлетворить возросшие потребности общества досуга, выражающихся в необходимости обеспечить занятость граждан, лечение, оздоровление, рекреацию и пр. Актуальность вопросов формирования социального благополучия особенно 
возрастает в условиях проявившегося в ходе глобализации стремления нивелировать некоторые черты национальных культур. Понимая важность социального благополучия и значимость нарастающей угрозы социуму, формируемой имеющимися глобальными проблемами современной цивилизации, государства и международная общественность стремятся принять соответствующие меры по улучшению ситуации, выстраивая эффективные социально-экономические модели, обеспечивающие благополучие в глобальном обществе. Так, 1 марта 2018 г. в Послании Президента Российской Федерации Федеральному Собранию Владимир Владимирович Путин в качестве основного приоритета роли и позиции государства в современном мире выделил прежде всего создание условий для развития и самореализации граждан, подчеркнув, что в основе всего лежит благополучие российских граждан.

Чем больше материальных ресурсов государство вкладывает в развитие туризма, например, формируя социальные туры для малообеспеченных граждан или занимаясь развитием туристкой инфраструктуры (прежде всего - транспортной и гостиничной), тем больше людей способны совершить туристскую поездку, организованную государством или туроператором. В России яркими примерами развития регионов, в том числе с целью туризма, являются:

- строительство Крымского моста;

- субсидирование авиарейсов в Крым;

- формирование пакетных туров, частично субсидированных государством;

- полная или частичная оплата путешествия по территории России работодателями (в пределах 50 тысяч рублей на одного человека начиная с 2019 г.) [18].

Как показывают многочисленные исследования, туризм становится необходимой составляющей благополучия современного человека, способного удовлетворить стремительно меняющиеся потребности туриста [19]. Большинство исследований приводят к выводу, что туризм как вид деятельности положительно влияет на туристов (обеспечивает удовлетворенность жизнью) и жителей туристических регионов (улучшает их самочувствие). Взаимосвязь между устойчивым развитием туризма и формированием благосостояния туристов и принимающих стран очевидна $[20,21]$. Всемирная туристская организация считает, что туризм может служить инструментом повышения благосостояния коренных общин определенных территорий и регионов [22]. В целом туризм как феномен современной жизни глобального сообщества становится неотъемлемым фактором формирования устойчивого социального благополучия.

\section{СПИСОК ЛИТЕРАТУРЫ}

1. UNWTO Tourism Highlights presents a concise overview of international tourism in the world based on the results for the year 2017 URL: https://www.e-unwto.org/doi/pdf/10.18111/9789284419876 (дата обращения 10.10.2018).

2. Матвеева А. Механизмы социализации личности в условиях постиндустриализма: монография. Казань: Бук, 2016. - 240 с.

3. Исрафилзаде С.Э. Влияние процесса глобализации на трансформацию туристской сферы общественной жизни // Эволюция современной науки: сборник статей международной научно-практической конференции. - Уфа: Омега Сайнс, 2017. - С. 247-251.

4. UNWTO. Glossary of tourism terms. URL: http://statistics.unwto.org/sites/all/files/docpdf/glossaryterms.pdf (дата обращения 10.10.2018).

5. Smith M.K. Issues in cultural tourism studies. - London: Routledge, 2016. -288 p.

6. Малышева Е.В. Потребительские практики в сфере туризма: когортный анализ: дис. ... канд. социол. наук. - Казань, 2014. - 275 с.

7. McCabe S., Johnson S. The happiness factor in tourism: Subjective well-being and social tourism // Annals of Tourism Research. - 2013. - V. 41. - P. 42-65.

8. Smith M.K., Diekmann A. Tourism and wellbeing // Annals of Tourism Research. - 2017. - V. 66. - P. 1-13. 
9. Coghlan A. Tourism and health: using positive psychology principles to maximise participants' wellbeing outcomes - a design concept for charity challenge tourism // Journal of Sustainable Tourism. - 2015. V. 23. - № 3. - P. 382-400.

10. Morgan N., Pritchard A., Sedgley D. Social tourism and well-being in later life // Annals of Tourism Research. - 2015. - № 52. - Р. 1-15.

11. Воскресенский В.Ю. Международный туризм. - М.: ЮНИТИ-ДАНА, 2015. - 463 с.

12. The Cornerstone of Research on Subjective Well-Being: Valid Assessment Methodology. URL: https://www.nobascholar.com/chapters/15/download.pdf (дата обращения 10.10.2018).

13. Loyko O.T. et al. Well-being as a Phenomenon: Research Paradigms of the Fifth Age // The European Proceedings of Social \& Behavioural Sciences (EpSBS). V. 19: Lifelong Wellbeing in the World (WELLSO 2016). - Nicosia, 2017. - V. 192016. - P. 438-443.

14. Karla Cripps. World's 10 most popular tourist destinations (and their future rivals). URL: https://edition.cnn.com/travel/article/world-most-popular-destinations-2017 (дата обращения 10.10.2018).

15. Country Overview by Country and Time // UNECE Statistical Database. URL: https://w3.unece.org/ PXWeb2015/pxweb/en/STAT/STAT_10-CountryOverviews_01-Figures/ZZZ_en_CoSummary_r.px (дата обращения 10.10.2018).

16. Filep S., Laing J., Csikszentmihalyi M. Positive tourism. - London: Routledge, 2016. - 232 p.

17. Александрова А.Ю. Международный туризм. - М.: КноРУС, 2015. - 459 с.

18. О внесении изменений в статьи 255 и 270 части второй Налогового кодекса Российской Федерации: федер. закон от 23 апреля 2018 г. № 113-Ф3. URL: http://www.consultant.ru/ document/cons_doc_LAW_296453/ (дата обращения 10.10.2018).

19. Nawijn J., Filep S. Two directions for future tourist well-being research. Annals of Tourism Research // Annals of Tourism Research. - 2016. - № 61. - pp. 221-223. DOI: 10.1016/j.annals.2016.07.007.

20. Quality of life (QOL) and well-being research in tourism / M. Uysal, M.J. Sirgy, E. Woo, H.L. Kim // Tourism Management. - 2016. - № 53. - P. 244-261.

21. Лойко О.Т. Устойчивое развитие и планирование в туризме: учебное пособие //Томск: Издательство ТПУ. - 2011. -358 с.

22. Buzinde C.N., Kalavar J.M., Melubo K. Tourism and community well-being: the case of the Maasai in Tanzania // Annals of Tourism Research. - 2014. - № 44. - P. 20-35.

Поступила 13.05.2019 2. 
UDC 101.1:316

\title{
TOURISM AS AN ELEMENT IN THE SPHERE OF SOCIAL WELL-BEING
}

\author{
Maria A. Aleksandrova, \\ aleksandrova@tpu.ru \\ National Research Tomsk Polytechnic University, \\ 30, Lenin Avenue, Tomsk, 634050, Russia.
}

Maria A. Aleksandrova, postgraduate student, National Research Tomsk Polytechnic University.

The relevance of the study is determined by the dynamic development of tourism. The article deals with the phenomenon of tourism as an element of the sphere of social well-being. The author analyzes the main characteristics of tourism, ensuring its development and involvement of the global society in tourism, and also reveals the role and importance of tourism in modern society. The aim of the research is to characterize tourism as an element of the sphere of social well-being. Methods: structural and functional analysis, the theory of structural functionalism, which allows characterizing the problems of the phenomenon of tourism, focused on achieving social well-being through self-realization and individual development. In accordance with the objectives set in the research the analytical method was used. It helps in considering scientific works, focused on socio-philosophical analysis of tourism and prosperity, which allowed identification and preparation of the significance of the phenomenon of tourism in today's global society. The author has applied the phenomenological approach, that allowed understanding tourism as a phenomenon of existence of society, which is the important area of its life and affects the feeling of human happiness, and subjective well-being, contributing, in its turn, shaping social welfare in general and increase the quality of life. Results. In modern society, well-being cannot be reduced only to material factors, since it also includes socio-cultural aspects. Considering tourism as a way to realize well-being, the author comes to the conclusion about the development of personal qualities of a person through the formation of his subjective well-being. Tourism as a phenomenon of global society, can expand the personal space of a person, which leads to implementation of its individual development strategies and self-improvement. The importance of tourism in formation of subjective well-being is obvious and it depends on the importance that a particular person attaches to tourism and the goals associated with it. All this confirms the social importance of tourism as an element of social wellbeing.

Key words: Tourism, travel, mass tourism, individual tourism, leisure society, well-being.

\section{REFERENCES}

1. UNWTO Tourism Highlights presents a concise overview of international tourism in the world based on the results for the year 2017. Available at: https://www.e-unwto.org/doi/pdf/10.18111/9789284419876 (accessed 10 October 2018).

2. Matveeva A. Mekhanizmy sotsializatsii lichnosti v usloviyakh postindustrializma [Mechanisms of personality socialization in the conditions of post-industrialism]. Kazan, Buk Publ., 2016. 240 p.

3. Israfilzade S.E. Vliyanie protsessa globalizatsii na transformatsiyu turistskoy sfery obshchestvennoy zhizni [The impact of globalization on transformation of the tourist sphere of public life]. Evolyutsiya sovremennoy nauki. Sbornik statey mezhdunarodnoy nauchno-prakticheskoy konferentsii [The evolution of modern science. Collection of articles of the international scientific-practical conference]. Ufa, Omega Sains Publ., 2017. pp. 247-251.

4. UNWTO. Glossary of tourism terms. Available at: http://statistics.unwto.org/sites/all/files/docpdf/ glossaryterms.pdf (accessed 10 October 2018).

5. Smith M.K. Issues in cultural tourism studies. London, Routledge, 2016. 288 p. 
6. Malysheva E.V. Potrebitelskie praktiki v sfere turizma: kogortny analiz. Diss. Kand. nauk [Consumer practices in tourism: a cohort analysis. Cand. Diss.]. Kazan, 2014. 275 p.

7. McCabe S., Johnson S. The happiness factor in tourism: Subjective well-being and social tourism. Annals of Tourism Research, 2013, vol. 41, pp. 42-65.

8. Smith M.K., Diekmann A. Tourism and wellbeing. Annals of Tourism Research, 2017, vol. 66, pp. 1-13.

9. Coghlan A. Tourism and health: using positive psychology principles to maximise participants' wellbeing outcomes - a design concept for charity challenge tourism. Journal of Sustainable Tourism, 2015, vol. 23, no. 3, pp. 382-400.

10. Morgan N., Pritchard A., Sedgley D. Social tourism and well-being in later life. Annals of Tourism Research, 2015, no. 52, pp. 1-15.

11. Voskresenskiy V.Yu. Mezhdunarodny turizm [International tourism]. Moscow, YUNITI-DANA Publ., 2015. $463 \mathrm{p}$.

12. The cornerstone of research on subjective well-being: Valid assessment methodology. Available at: https://www.nobascholar.com/chapters/15/download.pdf (accessed 10 October 2018).

13. Loyko O.T. Well-being as a Phenomenon: Research Paradigms of the Fifth Age. The European Proceedings of Social \& Behavioural Sciences (EpSBS). Vol. 19: Lifelong Wellbeing in the World (WELLSO 2016). Nicosia, 2017. Vol. 192016, pp. 438-443.

14. Karla Cripps. World's 10 most popular tourist destinations (and their future rivals). CNN travel. Available at: https://edition.cnn.com/travel/article/world-most-popular-destinations-2017 (accessed 10 October 2018).

15. Country Overview by Country and Time. UNECE Statistical Database. Available at: https://w3.unece.org/ PXWeb2015/pxweb/en/STAT/STAT_10-CountryOverviews_01-Figures/ZZZ_en_CoSummary_r.px (accessed 10 October 2018).

16. Filep S., Laing J., Csikszentmihalyi M. Positive tourism. London; Routledge, 2016. 232 p.

17. Aleksandrova A.Yu. Mezhdunarodny turizm [International tourism]. Moscow, KnoRUS Publ., 2015. 459 p.

18. vnesenii izmeneniy v stati 255 i 270 chasti vtoroy Nalogovogo kodeksa Rossiyskoy Federatsii [On Amendments to Articles 255 and 270 of Part Two of the Tax Code of the Russian Federation]. Federalny zakon ot 23 aprelya 2018 g. no. 113-FZ [Federal Law of April 23, 2018 N 113-FZ]. Available at: http://www.consultant.ru/document/cons_doc_LAW_296453/(accessed 10 October 2018).

19. Nawijn J., Filep S. Two directions for future tourist well-being research. Annals of Tourism Research, 2016, no. 61, pp. 221-223. DOI: 10.1016/j.annals.2016.07.007

20. Uysal M., Sirgy M.J., Woo E., Kim H.L. Quality of life (QOL) and well-being research in tourism. Tourism Management, 2016, no. 53, pp. 244-261.

21. Loyko O.T. Ustoychivoe razvitie i planirovanie v turizme [Sustainable development and tourism planning]. Tomsk, TPU Publ, 2011. 358 p.

22. Buzinde C.N., Kalavar J.M., Melubo K. Tourism and community well-being: the case of the Maasai in Tanzania. Annals of Tourism Research, 2014, no. 44, pp. 20-35.

Received: 13 May 2019. 